\title{
Cystic Fibrosis-Related Diabetes in Childhood
}

\author{
Stephen M.P. O'Riordan Mehul T. Dattani Peter C. Hindmarsh \\ Developmental Endocrinology Research Group, Clinical and Molecular Genetics Unit, Institute of Child Health, \\ University College London, London, UK
}

\section{Key Words}

Diabetes - Cystic fibrosis - Cystic fibrosis-related diabetes, children

\begin{abstract}
Since the early 1990 s the management of children with cystic fibrosis (CF) has come a long way and advances in both nutritional and medical care have resulted in a median age of survival of 30-35 years, as compared with a life expectancy of $<1$ year in the 1950s. The first definitive reports of glucose intolerance or diabetes in CF are from 1955. The combination of CF and related diabetes (CFRD) has a negative impact on survival. CFRD is now the most common complication of CF ( $50 \%$ of the CF patients will develop diabetes by the age of 30 years), and is associated with a 6-fold increase in morbidity and mortality. CFRD is usually asymptomatic and can remain undetected for up to 4 years prior to diagnosis. The objective of this report was to review the current literature (Medline and Pubmed searches) on CFRD in children and adolescents and provide a comprehensive report of incidence, prevalence and pathophysiology of insulin deficiency and insulin insensitivity. Along with survival and prognosis in CFRD the current management strategies in the diagnosis, monitoring and treatment of CFRD will also be addressed.

Copyright $\odot 2010$ S. Karger AG, Basel
\end{abstract}

\section{Introduction}

Cystic fibrosis (CF) is the most common lethal genetic autosomal recessive disease in Caucasians, with a worldwide prevalence of 1 in 2,500 live births. CF patients are now living well into adulthood, and nonpulmonary manifestations of the disease have become prevalent. CF-related diabetes (CFRD) has emerged as the most common comorbidity [1-9]. While CFRD shares features of both type 1 (T1D) and type 2 diabetes (T2D), there are important differences which necessitate a unique approach to diagnosis and management (table 1). Factors specific to CF that variably affect glucose metabolism include the state of respiratory infection and inflammation, increased energy expenditure, malnutrition, glucagon deficiency and gastrointestinal abnormalities (malabsorption, altered gastric emptying and intestinal motility, liver disease).

S.M.P.O. would like to acknowledge the support of the Institute of Child Health, National Institute of Health Research and Biomedical Research Centre and Novo-Nordisk, sponsor of the European Society for Paediatric Endocrinology Clinical Research Fellowship.

\section{KARGER}

Fax +4161306 1234

E-Mail karger@karger.ch

www.karger.com
(C) 2010 S. Karger AG, Basel

$1663-2818 / 10 / 0731-0015 \$ 26.00 / 0$

Accessible online at:

www.karger.com/hrp
Stephen O'Riordan

Developmental Endocrinology Research Group

Clinical Molecular Genetics Unit, Level 3, Institute of Child Health

30 Guilford Street, London WC1N 1EH (UK)

Tel. +44 207905 2877, Fax +44 207404 6191, E-Mail s.oriordan@ich.ucl.ac.uk 
Table 1. A comparison of T1D, T2D and CFRD

\begin{tabular}{llll}
\hline & T1D & T2D & CFRD \\
\hline Onset & acute & insidious & insidious \\
Peak age at onset, years & children and adolescents & adults & $18-24$ \\
Antibody (+) & yes & no & probably no \\
Insulin secretion & eventually absent & decreased & severely decreased but not absent \\
Insulin sensitivity & somewhat decreased & severely decreased & somewhat decreased \\
Treatment & insulin & diet, oral medications, insulin & insulin \\
Microvascular complications & yes & yes & yes but less \\
Macrovascular complications & yes & yes & no \\
Cause of death & cardiovascular disease & cardiovascular disease & pulmonary disease \\
\hline
\end{tabular}

${ }^{1}$ Insulin sensitivity becomes severely decreased during acute illness.

Table 2. Oral glucose tolerance categories in $\mathrm{CF}$ as defined by the North American CF Consensus Conference

\begin{tabular}{lcc}
\hline Category & FPG, mg/dl & 2-hour PG, mg/dl \\
\hline NGT & $<126(7.0)$ & $<140(7.8)$ \\
Indeterminate & $<126(7.0)$ & $140-199(7.8-11.1)^{*}$ \\
IGT & $<126(7.0)$ & $140-199(7.8-11.1)$ \\
CFRD without fasting hyperglycaemia & $<126(7.0)$ & $\geq 200(11.1)$ \\
CFRD with fasting hyperglycaemia & $\geq 126(7.0)$ & OGTT not necessary \\
\hline
\end{tabular}

* NGT by fasting and $2 \mathrm{~h}$ OGTT glucose determination, but mid-OGTT glucose levels $\geq 200 \mathrm{mg} / \mathrm{dl}(11.1 \mathrm{mmol} / \mathrm{l})$ or postprandial hyperglycemia determined by CGM in the absence of symptoms.

The OGTT is performed by giving an oral glucose load of $1.75 \mathrm{~g} / \mathrm{kg}$ body weight (maximum $=75 \mathrm{~g}$ ) to fasting patients. FPG and 2-hour PG are measured. The patient should have consumed at least $150 \mathrm{~g} /$ day of carbohydrate during the 3 days prior to testing $(600 \mathrm{kcal})$. Most CF patients consume much more carbohydrate than this on a daily basis. Figures in parentheses indicate millimol/liter.

\section{Diagnostic Definitions}

The American Diabetes Association and International Society of Pediatric Adolescent Diabetes place CFRD under the diagnostic heading 'Other specific types of diabetes; diseases of the exocrine pancreas'. The diagnosis of CFRD is confirmed by the presence of fasting or random hyperglycemia or a diabetic oral glucose tolerance test (OGTT). Standard OGTT categories were modified by the 1998 North American CFRD Consensus Committee to differentiate diabetes with and without fasting hyperglycemia (table 2), based on the suggestion that the prognosis may differ between these 2 groups in CF [8,9]. A further diagnostic category has been proposed as: 'indeterminate' by the North American CF Consensus Conference in 2009. This category is currently defined as NGT by fasting and 2-hour OGTT glucose determination, but mid-OGTT glucose concentrations $\geq 200 \mathrm{mg} / \mathrm{dl}(11.1 \mathrm{mmol} / \mathrm{l})$ or postprandial hyperglycemia determined by continuous glucose monitoring (CGM) in the absence of symptoms.

CFRD falls at 1 end of a spectrum of progressive glucose tolerance abnormalities. Few CF patients have completely normal glucose tolerance (NGT) at all times. The earliest change is variable, intermittent postprandial hyperglycemia followed by impaired glucose tolerance (IGT), diabetes without fasting hyperglycemia and diabetes with fasting hyperglycemia. Isolated impaired fasting glucose is rare in $\mathrm{CF}$, and patients tend to maintain a normal fasting glucose concentration long after their postprandial or 2-hour OGTT glucose is in the diabetic range.

There may be considerable fluctuation in the degree of glucose intolerance; this varies from individual to individual and relative to the degree of insulin insensitivity. 
The insulin insensitivity in CF patients is often variable and dependent on changing infectious status, medications and nutrition. Someone with CF who has overt diabetes during an infective exacerbation may return to NGT weeks or months later [9].

\section{Incidence and Prevalence}

The incidence and prevalence of glucose intolerance and CFRD in patients with CF is rising and higher than any other age-matched group including the Pima Indians [10]. An age-dependent incidence of 4-9\% per year was found in Denmark [11]. The reported prevalence of CFRD varies depending on the monitoring and diagnostic criteria, and may be underestimated at centers which do not perform universal monitoring on all patients. While it can occur at any age, CFRD prevalence clearly increases as patients get older. Young age does not, however, preclude a diagnosis of CFRD. There are isolated case reports of infants with CFRD; in the USA $9 \%$ of the 5 - to 9 -yearold and $26 \%$ of the 10 - to 20 -year-old CF patients were reported to have CFRD [12] (fig. 1). In Denmark, where all children with CF undergo annual OGTT, 50\% of the patients developed CFRD by 30 years of age [13], and in the USA this may be as high as $70 \%$ by the age of 30 years [14].

The European Epidemiologic Registry of Cystic Fibrosis reported a 5 and $13 \%$ prevalence in the age groups 10-14 and 15-19 years, respectively [15]. A recent prospective trial from Ireland found similar prevalence figures: NGT 69\%, IGT 14\% and CFRD 17\% in the 10-19 years age group [16]. Repeated OGTTs have shown that the glucose tolerance status can vary from year to year in CF patients [11].

\section{Pathophysiology of CFRD}

\section{Genetics of CFRD and Relation to the CF Mutation}

CFRD mainly occurs in people with CF mutations that are associated with severe disease (c.Phe508del) and are related to exocrine pancreatic insufficiency [17-19]. There does not appear to be a correlation with known T1D susceptibility genes such as HLA class II [20] or insulin VNTR [17], but a possible link has been described between CFRD and T2D susceptibility genes associated with inflammation such as the genes encoding tumor necrosis factor [20], heat shock protein [20,21] and calpain $10[22]$.

CFRD in Children and Adolescents

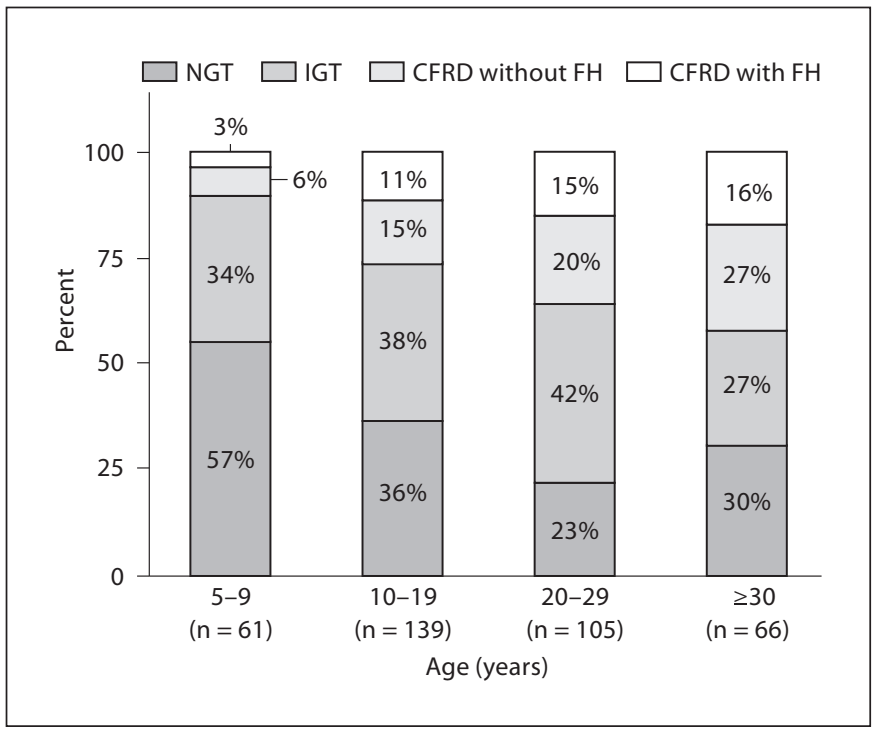

Fig. 1. Glucose tolerance categories in CF patients at the University of Minnesota, expressed as percent prevalence within age groups. $\mathrm{n}=$ Total number of patients studied within that age group (from Hardin and Moran [6]).

\section{Pancreatic Pathology}

Abnormal chloride channel function in CF results in thick viscous secretions causing obstructive damage to the exocrine pancreas with progressive fibrosis and fatty infiltration. A possible mechanism for the abnormal glucose homeostasis and pathophysiology in CFRD is depicted in figure 2 . This results in disruption and destruction of islet architecture leading to loss of endocrine- $\beta$, $-\alpha$ and polypeptide cells. The correlation between the degree of $\beta$-cell destruction and development of diabetes is poor, and postmortem studies have not shown a greater loss of pancreatic islets in patients with CFRD compared to those with normal glucose tolerance. Islet amyloid polypeptide (IAPP) deposition, which is characteristic of T2D, was found on autopsy in $69 \%$ of the CF patients with CFRD, while it was absent in those without diabetes [23]. This suggests a common pathologic mechanism between CFRD and T2D in that $\beta$-cell failure predominates.

$\beta$-Cell dysfunction does not appear to be related to autoimmune disease in CF. While one study reported a high prevalence of T1D-associated autoantibodies in CF patients both with and without diabetes, these data have not been verified by other investigators [20]. Isolated case reports of autoantibody-positive individuals with CFRD suggest that there may be occasional patients with coexisting T1D [20].

Horm Res Paediatr 2010;73:15-24 
Fig. 2. Possible mechanism for abnormal glucose homeostasis and pathophysiology in CFRD patients.

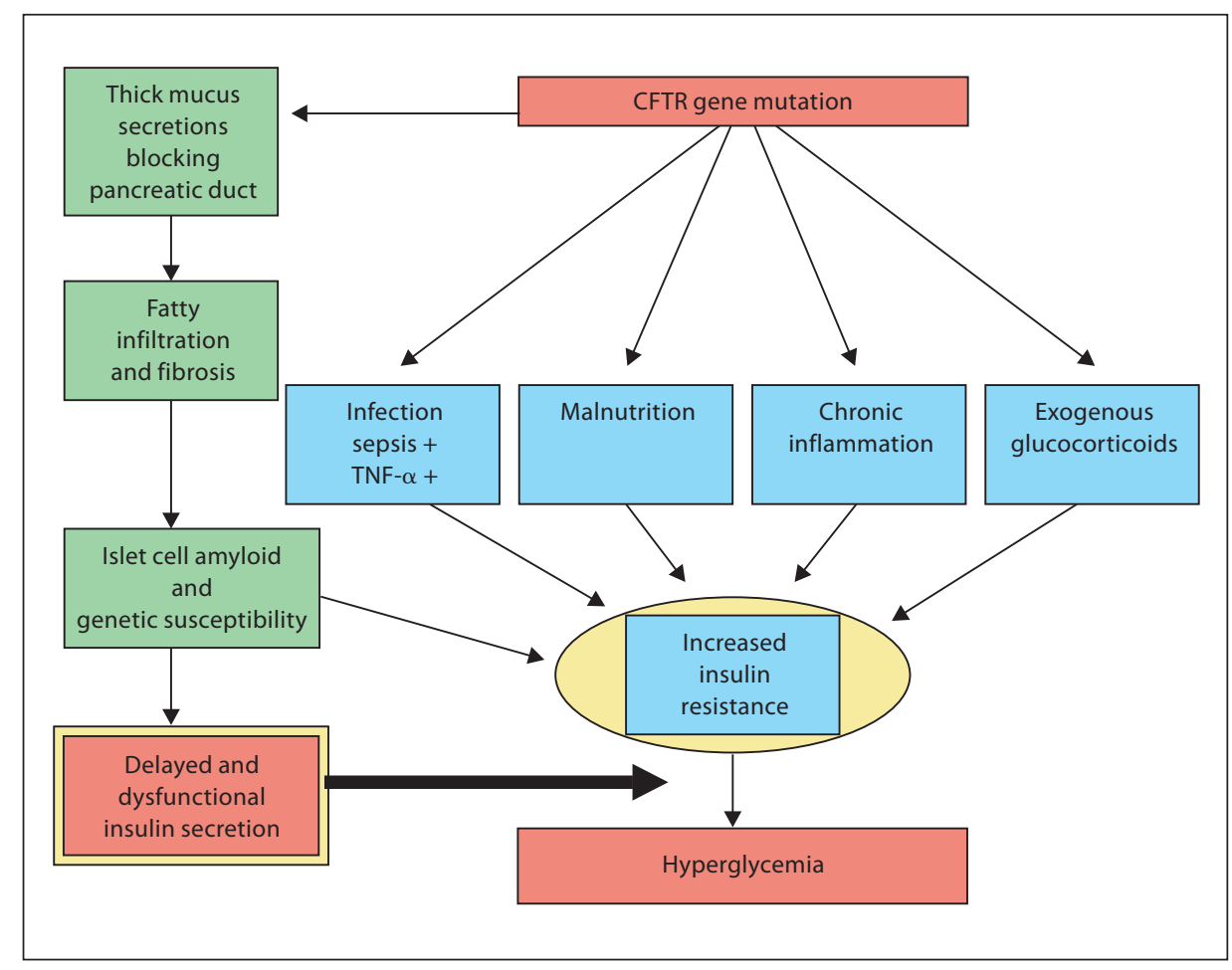

\section{The Role of Insulin Deficiency}

The primary defect in CFRD is severe but not absolute insulin deficiency. Virtually all exocrine insufficient patients with CF, with and without diabetes, show evidence of $\beta$-cell dysfunction $[9,11]$. Fasting insulin and $C$ peptide concentrations may be normal, but there is delay and blunting of peak insulin secretion during a standard OGTT. The time to peak insulin secretion is $90-120 \mathrm{~min}$ in people with CFRD compared to 30-60 min in healthy subjects. This effect is more pronounced with worsening glycemic status. Delayed insulin secretion during the OGTT is related to loss of first-phase insulin secretion, which is found even in CF patients with normal glucose tolerance [24].

\section{The Role of Insulin Insensitivity}

In CF patients without diabetes, insulin sensitivity has been reported as normal or decreased $[9,25]$. These differences are most likely related to the underlying state of health of the individual patient, since infection and inflammation influence insulin sensitivity [26]. CF patients with diabetes have been reported to be insulin insensitive, including both decreased peripheral glucose uptake and poor insulin suppression of hepatic glucose production $[9,27]$. While insulin insensitivity is generally mod- est in CF patients who are in their baseline state of health, it can become acutely severe during infectious exacerbations. Insulin insensitivity is not as important as insulin deficiency in the development of CFRD [27].

\section{Box 1: Key Points on CFRD}

- CFRD is a rapidly growing area of importance for CF children and adults.

- CFRD is the most common comorbidity in persons with CF, with a prevalence of about $50 \%$ by 30 years of age.

- CFRD is generally insidious in onset, and thus screening is necessary. Routine annual OGTT is generally recommended. CGM can detect abnormalities earlier than the OGTT, but the clinical significance of these early changes is unknown.

- CFRD is predominantly an insulin deficiency state. Insulin deficiency leads to protein catabolism, weight loss, pulmonary function decline and early death from lung disease. Clinical decline can be seen 2-6 years prior to the diagnosis of diabetes.

- CFRD is associated with increased morbidity and mortality once CFRD is diagnosed.

- Early intervention with insulin has been shown to reverse clinical deterioration, even in persons with CFRD without fasting hyperglycemia. 


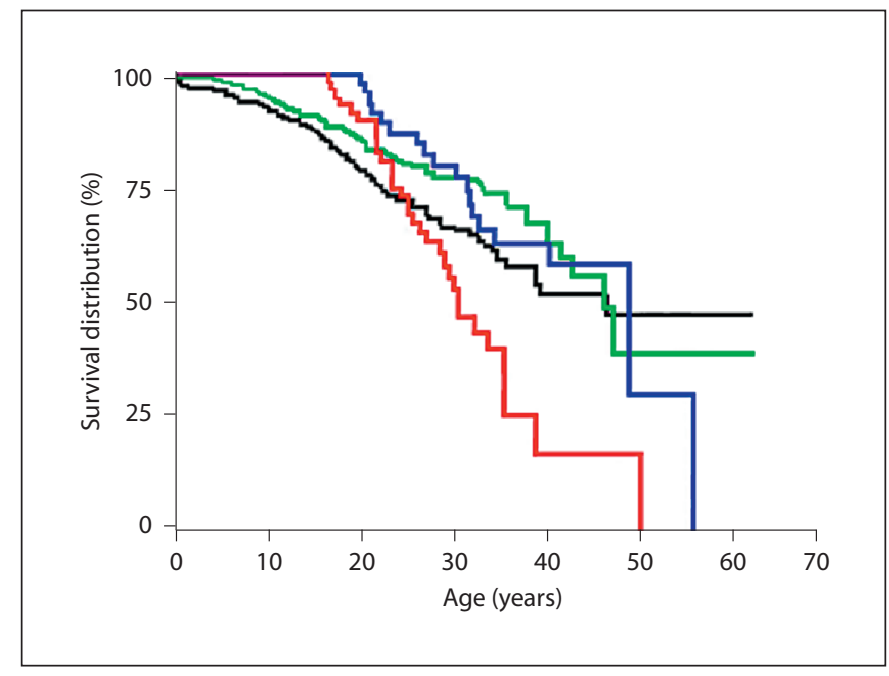

Fig. 3. Survival curves for CF men without diabetes (green, median survival $=49.5$ years), CF men with diabetes (blue, median $=47.4$ years), CF women without diabetes (black, median $=$ 47.0 years) and CF women with diabetes (red, median survival $=$ 30.7 years) [2].

\section{Survival and Prognosis}

\section{Increased Mortality in CFRD}

The presence of CFRD is associated with worsening lung function, poorer nutritional status and decreased survival compared to CF patients without diabetes $[5,9$, $15,28-33]$. In a retrospective study of 448 patients with CF followed for 10 years, 25\% of those with CFRD were alive at 30 years compared to $60 \%$ of those without CFRD [28]. Prospective Danish data found that patients with CFRD had a median survival age of 24 years as compared to 34 years in nondiabetic controls with $\mathrm{CF}$ [15]. In the $\mathrm{UK}$, diabetes was associated with significantly worse lung function in women but not in men with CF [34]. Concerning data demonstrate a marked gender difference in survival in CFRD. Of 1,081 CF patients followed for 15 years at the University of Minnesota, the median survival was 47-49 years for male and female subjects without CFRD, and this was reduced to 31 years for female subjects with CFRD, not seen in males [2] (fig. 3). The lack of gender differences was confirmed by a large prospective French cohort ( $n=237$ children with CF) following participants for 17 years after initial assessment [35]. This study showed that early impairment was associated with lower survival rates and higher rates of lung transplantation regardless of gender [35]. Recent follow-up data presented at the American Diabetes Association from Minnesota have identified that these survival gender differences do not remain at 10-15 years follow-up [36].

\section{Increased Morbidity in the Prediabetic State}

Several studies have shown that an insidious decline in clinical status occurs 2-6 years before the diagnosis of CFRD $[5,28,29,31,32]$. In a prospective study, the decline in pulmonary function over 4 years was greatest in CF patients with diabetes; this was less so in IGT and the least in patients with NGT [5]. Pulmonary deterioration correlated with the degree of insulin deficiency at baseline. This was supported by a recent trial from the UK; however, this study confirmed that the decline in BMI and lung function was more pronounced in those with younger-onset CFRD compared to diagnosis at an older age [37]. This study also highlighted that those who developed CFRD 6 years earlier were twice as likely to need oral nutritional supplements and 4 times more likely to require enteral feeding [37]. Given the known association between protein catabolism, malnutrition and death in $\mathrm{CF}$, and given the potent anabolic effect of insulin, the nutritional impact of insulin deficiency may be of greater consequence in CF than the metabolic impact of hyperglycemia.

\section{Microvascular Complications}

Diabetes microvascular complications have been described in case reports and small series of CFRD patients, sometimes with significant morbidity such as blindness, glaucoma, hypertension and renal failure [38-40]. In Denmark, $36 \%$ of the patients with $>10$ years duration of diabetes were reported to have retinopathy [41]. In a larger series of 285 CFRD patients, none of the patients without fasting hyperglycemia (up to 14 years duration) had microvascular complications, and in those with fasting hyperglycemia, complications were rare before 10 years duration of disease [42]. However, of the 39 subjects who had CFRD with fasting hyperglycemia of $>10$ years duration, microalbuminuria was found in $14 \%$, retinopathy in $16 \%$, neuropathy in $55 \%$ and gastropathy in $50 \%$. While the prevalence of diabetes microvascular complications appears to be lower in CFRD than in other forms of diabetes, it remains important to screen for these complications 5 years after the diagnosis of CFRD is made.

\section{Macrovascular Complications}

Atherosclerotic cardiovascular disease has never been reported in CF or CFRD, despite the fact that these patients are living longer. CF patients generally have low 
Table 3. Clinical symptoms which may indicate the presence of CFRD [8]

- Unexplained polyuria or polydipsia

- Failure to gain or maintain weight despite nutritional intervention

- Poor growth velocity

- Delayed progression of puberty

- Unexplained chronic decline in pulmonary function

cholesterol concentrations, although isolated hypertriglyceridemia does occur, perhaps related to inflammation [43].

\section{Background Diagnosis and Treatment Considerations}

\section{Clinical Features of CFRD}

The median age at CFRD diagnosis is between 18 and 24 years, although it can present at any age $[9,11,15]$. It appears to present at a younger age in girls $[2,9,11,18$, $28,44]$. CFRD develops insidiously and patients may be asymptomatic for years. Symptoms of CFRD are listed in table 3. Diabetic ketoacidosis can occur at the time of initial presentation or during the clinical course of CFRD. Diabetic ketoacidosis is rare in CFRD children, most likely due to the persistence of endogenous insulin secretion or because glucagon secretion is also impaired [24, 44-47]. A recent case report has also described cerebral edema in a patient with diabetic ketoacidosis and CFRD [48]. CFRD often first presents during situations where insulin sensitivity is reduced, presumably by unmasking the underlying $\beta$-cell defect $[11,38,49,50]$, such as with: acute pulmonary infection, chronic severe lung disease, glucocorticoid therapy, high-carbohydrate food supplementation (oral, intravenous or percutaneous gastrostomy tubes) and in association with immunosuppressive regimens following transplantation. The incidence of CFRD is higher in those with hepatic disease [30].

\section{Monitoring for CFRD}

Two thirds of the patients with CFRD were asymptomatic and only one third had symptoms of polyuria or polydipsia at the time of diagnosis in a prospective Danish study of 191 patients [11]. Patients who develop overt symptoms of hyperglycemia on presentation have a relatively greater decline in pulmonary function and weight loss as compared with those identified on monitoring [5,
$29,31,32]$. Therefore it is important to identify patients by monitoring before the onset of symptoms. The following methods of CFRD monitoring have been considered: hemoglobin $\mathrm{A}_{1 \mathrm{c}}\left(\mathrm{HbA}_{1 \mathrm{c}}\right)$, random or fasting glucose concentrations, OGTT and continuous glucose monitoring (CGM).

$\mathrm{HbA}_{1 \mathrm{c}}$ as a Monitoring Tool

$\mathrm{HbA}_{1 \mathrm{c}}$ has been shown by several investigators to be unreliable in the diagnosis of CFRD $[11,28] . \mathrm{HbA}_{1 \mathrm{c}}$ is often normal, regardless of the degree of hyperglycemia. In Denmark, only $16 \%$ of the CF patients had elevated $\mathrm{HbA}_{1 \mathrm{c}}$ values at the time of diagnosis of CFRD [11]. This is hypothesized but not proven to be related to increased red blood cell turnover related to inflammation in patients with $\mathrm{CF}$.

Random and Fasting Blood Glucose Concentrations for CFRD Monitoring

While hyperglycemia is diagnostic for diabetes, normal fasting or random blood glucose concentrations do not exclude a diagnosis of diabetes in CF.

\section{Oral Glucose Tolerance Testing}

The OGTT is the standard monitoring test for CFRD in much of Europe [11], while in North America, measurement of fasting blood glucose concentration is more common [8]. Diabetes without fasting hyperglycemia can only be detected by OGTT. Nearly two thirds of the adults with a diagnosis of CFRD do not have fasting hyperglycemia $[12,47]$. It is important to identify these individuals because they are at high risk for both significant lung function decline [5] and for progression to fasting hyperglycemia [14] and its associated complications.

\section{Continuous Glucose Monitoring}

CGM has the potential to diagnose glucose tolerance abnormalities earlier than the OGTT, although to date the clinical significance of this remains to be determined [9]. CGM can highlight trends in glycemia not previously apparent to clinicians and patients, especially in the home environment, this option having been previously unavailable in children and adolescents with CF. CGM has now been validated for use in children and adolescents with CF [51]. Although currently an important research tool in assessment of glycemia in children and adolescents with CF, CGM may become more important in the management and annual monitoring for diabetes in the near future [9]. 
Table 4. Differences in the dietary management of T1D and T2D versus CFRD (UK CF Trust Diabetes Working Group and CF Consensus Conference)

\begin{tabular}{|c|c|c|}
\hline & $\mathrm{T} 1 \mathrm{D}$ and $\mathrm{T} 2 \mathrm{D}$ & CFRD \\
\hline Calories & $\begin{array}{l}\leq 100 \% \text { of normal for age and gender - } \\
\text { often have to watch or restrict calories } \\
\text { to prevent overweight }\end{array}$ & $\begin{array}{l}\text { usually require } 120-150 \% \text { (or more) of normal } \\
\text { caloric intake for age and gender to prevent } \\
\text { underweight }\end{array}$ \\
\hline Fat & $<35 \%$ of total energy & $40 \%$ of total energy \\
\hline Refined sugars & up to $10 \%$ of total energy & no restriction \\
\hline Carbohydrate & $45-60 \%$ of total energy & $45-50 \%$ of total energy \\
\hline Dietary fiber & $\begin{array}{l}\text { no quantitative recommendation but } \\
\text { encouraged due to beneficial effects }\end{array}$ & $\begin{array}{l}\text { encouraged in the well nourished, but in poorly } \\
\text { nourished patients, it may compromise energy intake }\end{array}$ \\
\hline Protein & $\begin{array}{l}10-20 \% \text { of total energy; not }>1 \text { g per } \\
\text { kg body weight }\end{array}$ & $200 \%$ of reference nutrient intake \\
\hline Salt & low intake $\leq 6 \mathrm{~g} /$ day & increased requirement - unrestricted intake \\
\hline
\end{tabular}

\section{Treatment of CFRD}

\section{Medical Nutritional Therapy}

Malnutrition is well known to be associated with poor growth, pubertal delay, diminished lung function and early death in CF. CF consensus guidelines stress the importance of a high-calorie, high-fat diet [37, 52]. There is no evidence at present to suggest that these dietary recommendations should be reconsidered in CF patients who develop diabetes, since they do not appear to be at risk for development of macrovascular disease. Many CF patients rely on refined sugars as a source of calories, and restriction may impact on their nutritional status. It is important that those with CFRD learn to adjust their insulin dose to match their carbohydrate intake [37]. Table 4 compares the CFRD to conventional diabetes diets.

\section{Insulin Therapy}

At present insulin is the only recommended medical therapy for CFRD $[8,9]$. Many different regimens are possible depending on individual patient needs. As in other forms of diabetes, effective basal-bolus therapy can be accomplished with an insulin pump, or with a combination of long-acting basal insulin and rapid-acting insulin to cover carbohydrates and correct hyperglycemia [53]. A recent study by Hardin et al. [54] reported 10 young adults with CFRD treated on insulin pump therapy and monitored prospectively for a 6 -month period. All reported improvements in BMI and lung function and a reduction in total body catabolism. Previous studies have suggested that insulin therapy stabilizes lung function and improves nutritional status in patients with CFRD $[29,31,32,55]$. There are no definitive results to date on the benefits of insulin therapy for CF children and adolescents with mildly impaired glucose tolerance [9].

\section{Oral Therapeutic Agents}

Oral diabetes agents are currently not recommended in CFRD [8, 9]. A Cochrane review identified 20 references to 14 studies, but none were randomized controlled trials [56]. The insulin secretagogue repaglinide increased endogenous insulin concentrations but was less effective than rapid-acting insulin at regulating postprandial hyperglycemia in an experimental setting [57]. Concern has been expressed over the use of sulphonylureas in CFRD because of evidence that they bind to and inhibit CFTR, and as early experience suggested problems with hypoglycemia with these agents in CF. Agents that increase insulin sensitivity are unlikely to be effective as monotherapy in CFRD, since insulin insensitivity is not a major etiological factor. The gastrointestinal side effects of metformin such as nausea, diarrhea and abdominal discomfort are unacceptable to most patients with CF [58]. Thiazolidinediones have recently been associated with osteoporosis which limits the use of this drug in CF. There are no data on the use of incretins in CF, although those that decrease gastric emptying would not be expected to be good candidates for this population. 


\section{Adherence in Children and Adolescents with CFRD}

Adherence is defined as an 'active, voluntary, collaborative involvement of the patient in a mutually acceptable course of behavior to produce a desired preventative or therapeutic result'. Poor adherence to medical advice and treatment in chronic illness is well documented, with reports of patient adherence rarely exceeding $80 \%$ and more often falling between 30 and $70 \%$ [59]. The extent to which people adhere to recommended treatments depends on the complexity and longevity of both the disease and its treatment. The treatment of CF presents a particularly difficult challenge for patients and their families because it involves a time-consuming, complex daily medical regimen [60]. A second diagnosis of CFRD adds significantly to the complexity of this medical regimen, as patients are now required to undertake regular home blood glucose monitoring and insulin injections daily.

Poor compliance and lack of adherence to treatment is frequent in patients with chronic illness. It is an important clinical problem that can lead to unnecessary hospitalizations, increased risk for illness-related complications and increased health care costs. Adherence is particularly problematic as children move into adolescence. There are a number of factors involved in this: a lack of developmentally appropriate information, misconceptions about treatment, struggles for control and independence, striving for normality, stressors in the home environment and anxiety [8]. Finally, the main aim for adolescents and adults with CF and diabetes is independent care for themselves, and this is what empowers the patient to manage dual chronic illnesses. Parent and family supports for those with the new diagnosis of CFRD are essential and must be incorporated into the management plan to ensure adequate home support is provided.

\section{Inpatient Management of CFRD}

During an acute illness, patients with CF are at high risk of developing hyperglycemia [8]. There are no specific studies of the benefits of maintaining euglycemia in hospitalized CF patients, but data from other populations have been extrapolated to suggest that intensive insulin therapy may be beneficial in this setting. Insulin requirements are often quite high during acute illness. CFRD patients who regularly receive insulin require far more, often up to 4 times their usual dose. It is important to remember that the insulin dose must be aggressively reduced as the patient improves. There are many CF patients whose blood glucose concentrations return to normal after the illness resolves, at which time insulin therapy can be discontinued [8].
The primary purpose for establishing a diagnosis is to identify the expected outcome and to inform treatment decisions. The American Diabetes Association and WHO diabetes diagnostic criteria have changed over time to reflect new information regarding the correlation between the level of hyperglycemia and the risk of microvascular and macrovascular complications in T1D and T2D. Although these complications occur, they are of less concern in CFRD than the impact of diabetes on death from pulmonary disease and malnutrition. For IGT, there are not sufficient data at present to determine a 'cutoff' point or a particular degree of hyperglycemia and/or insulin deficiency which confers added risk.

\section{Box 2: Key Points for Treatment and Monitoring of CFRD}

- CFRD patients die from chronic, inflammatory lung disease, and thus treatment of the $\mathrm{CF}$ takes precedence and follows the usual recommendations for this population.

- As for all persons with CF, the energy requirements are at least $150 \%$ of normal; with a goal of about $40 \%$ fat, $20 \%$ protein and $40 \%$ carbohydrates. Typically these patients eat at least 3 meals and 3 snacks per day.

- Children and adolescents with IGT $^{1}$ and CFRD without fasting hyperglycaemia (CFRD-FH) ${ }^{2}$ must be monitored closely for the evolution of frank CFRD.

- The pancreatic supplements are essential at each meal and snack.

- Modifications should be made according to the individual's needs.

- Self-care education programs promote independence and encourage patients to adjust diet and insulin doses themselves.

- Insulin is the only recommended treatment for CFRD.

- Insulin provides an anabolic effect as well as normoglycemia.

- The insulin regimen should be adjusted to match the diet rather than asking patients to change their diet to fit an insulin regimen. This generally requires carbohydrate counting and matching insulin to carbohydrate intake.

- Insulin can be delivered by multiple daily injections or through insulin pump therapy.

- Checking with home blood glucose monitoring or CGM is important.

${ }^{1}$ IGT state may require insulin in case of severe deterioration in lung function, poor growth, static weight gain or symptoms of diabetes.

${ }^{2}$ CFRD-FH patients are at risk of progressing to fasting hyperglycemia and frank diabetes. Both IGT and CFRD-FH children must be monitored closely and each case must be individualized in the hands of an experienced pediatric endocrinologist in the management of CFRD. 


\section{References}

1 Brennan AL, Geddes DM, Gyi KM, Baker EH: Clinical importance of cystic fibrosisrelated diabetes. J Cyst Fibros 2004;3:209222.

2 Milla CE, Billings J, Moran A: Diabetes is associated with dramatically decreased survival in female but not male subjects with cystic fibrosis. Diabetes Care 2005;28:21412144.

3 Moran A: Diagnosis, screening, and management of cystic fibrosis-related diabetes. Curr Diabetes Rep 2002;2:111-115.

4 Moran A: Cystic fibrosis-related diabetes: an approach to diagnosis and management. Pediatr Diabetes 2000;1:41-48.

5 Milla CE, Warwick WJ, Moran A: Trends in pulmonary function in patients with cystic fibrosis correlate with the degree of glucose intolerance at baseline. Am J Respir Crit Care Med 2000;162:891-895.

6 Hardin DS, Moran A: Diabetes mellitus in cystic fibrosis. Endocrinol Metab Clin North Am 1999;28:787-800, ix.

7 Cystic Fibrosis Foundation: Cystic Fibrosis Foundation Patient Registry Annual Data Report. Bethesda, CFF, 2001.

$>8$ Moran A, Hardin D, Rodman D, Allen HF, Beall RJ, Borowitz D, Brunzell C, Campbell PW 3rd, Chesrown SE, Duchow C, Fink RJ, Fitzsimmons SC, Hamilton N, Hirsch I, Howenstine MS, Klein DJ, Madhun Z, Pencharz PB, Quittner AL, Robbins MK, Schindler T, Schissel K, Schwarzenberg SJ, Stallings VA, Zipf WB, et al: Diagnosis, screening and management of cystic fibrosis related diabetes mellitus: a consensus conference report. Diabetes Res Clin Pract 1999; 45:61-73.

9 O'Riordan SM, Robinson PD, Donaghue KC, Moran A: ISPAD Clinical Practice Consensus Guidelines 2009 Compendium: management of cystic fibrosis-related diabetes in children and adolescents. Pediatr Diabetes 2009; 10:43-50.

10 McCance DR, Hanson RL, Charles MA, Jacobsson LT, Pettitt DJ, Bennett PH, Knowler WC: Comparison of tests for glycated haemoglobin and fasting and two-hour plasma glucose concentrations as diagnostic methods for diabetes. BMJ 1994;308:1323-1328.

-11 Lanng S, Hansen A, Thorsteinsson B, Nerup J, Koch C: Glucose tolerance in patients with cystic fibrosis: five-year prospective study. BMJ 1995;311:655-659.

12 Moran A, Doherty L, Wang X, Thomas W: Abnormal glucose metabolism in cystic fibrosis. J Pediatr 1998;133:10-17.

13 Lanng S: Glucose intolerance in cystic fibrosis patients. Paediatr Respir Rev 2001;2:253259.

14 Schwarzenberg SJ, Thomas W, Olsen TW, Grover T, Walk D, Milla C, Moran A: Microvascular complications in cystic fibrosis related diabetes. Diabetes Care 2007;30:10561061.
15 Koch C, Rainisio M, Madessani U, Harms HK, Hodson ME, Mastella G, McKenzie SG, Navarro J, Strandvik B: Presence of cystic fibrosis-related diabetes mellitus is tightly linked to poor lung function in patients with cystic fibrosis: data from the European Epidemiologic Registry of Cystic Fibrosis. Pediatr Pulmonol 2001;32:343-350.

16 O'Riordan S MPG, S. Hoey H, Costigan C: Demographics and prevalence of glucose intolerance and cystic fibrosis related diabetes in 167 cystic fibrosis children. Diabetes 2006; 55:A224-A224.

17 O’Riordan SGA, Ennis S, George S, Hand E, Costigan C, Murphy N, Roche E, Hoey H: Genetics of cystic fibrosis related diabetes and nondiabetes. Horm Res 2007;68(suppl 1): 44-69.

18 Rosenecker J, Eichler I, Kuhn L, Harms HK, Von der Hardt H: Genetic determination of diabetes mellitus in patients with cystic fibrosis. J Pediatrics 1995;127:441-443.

19 Koch C, Cuppens H, Rainisio M, Madessani U, Harms H, Hodson M, Mastella G, Navarro J, Strandvik B, McKenzie S: European Epidemiologic Registry of Cystic Fibrosis (ERCF): comparison of major disease manifestations between patients with different classes of mutations. Pediatr Pulmonol 2001; 31:1-12.

20 Lanng S, Thorsteinsson B, Pociot F, et al: Diabetes mellitus in cystic fibrosis: genetic and immunloogical markers. Acta Paediatr Scand 1993;82:150-154.

21 Jensen P, Johansen HK, Carmi P, Hoiby N, Cohen IR: Autoantibodies to pancreatic hsp60 precede the development of glucose intolerance in patients with cystic fibrosis. J Autoimmun 2001;17:165-172.

22 Derbel S, Doumaguet C, Hubert D, MosnierPudar H, Grabar S, Chelly J, Bienvenu T: Calpain 10 and development of diabetes mellitus in cystic fibrosis. J Cyst Fibros 2006;5:4751.

23 Couce M, O’Brien TD, Moran A, Roche PC, Butler PC: Diabetes mellitus in cystic fibrosis is characterized by islet amyloidosis. J Clin Endocrinol Metab 1996;81:1267-1272.

24 Moran A, Diem P, Klein DJ, Levitt MD, Robertson RP: Pancreatic endocrine function in cystic fibrosis. J Pediatr 1991;118:715-723.

25 Holl RW, Heinze E, Wolf A, Rank M, Teller WM: Reduced pancreatic insulin release and reduced peripheral insulin sensitivity contribute to hyperglycaemia in cystic fibrosis. Eur J Pediatr 1995;154:356-361.

26 Hardin DS, Leblanc A, Marshall G, Seilheimer DK: Mechanisms of insulin resistance in cystic fibrosis. Am J Physiol Endocrinol Metab 2001;281:E1022-1028.

27 Moran AP, Pyzdrowski KL, Weinreb J, Kahn BB, Smith S A, Adams KS, Seaquist ER: Insulin sensitivity in cystic fibrosis. Diabetes 1994;43:1020-1026.
28 Finkelstein SM, Wielinski CL, Elliott GR, Warwick WJ, Barbosa J, Wu SC, Klein DJ: Diabetes mellitus associated with cystic fibrosis. J Pediatr 1988;112:373-377.

29 Lanng S, Thorsteinsson B, Nerup J, Koch C: Influence of the development of diabetes mellitus on clinical status in patients with cystic fibrosis. Eur J Pediatr 1992;151:684687.

30 Marshall BC, Butler SM, Stoddard M, Moran AM, Liou TG, Morgan WJ: Epidemiology of cystic fibrosis-related diabetes. J Pediatr 2005; 146:681-687.

31 Nousia-Arvanitakis S, Galli-Tsinopoulou A, Karamouzis M: Insulin improves clinical status of patients with cystic-fibrosis-related diabetes mellitus. Acta Paediatr 2001;90: 515-519.

32 Rolon MA, Benali K, Munck A, Navarro J, Clement A, Tubiana-Rufi N, Czernichow P, Polak M: Cystic fibrosis-related diabetes mellitus: clinical impact of prediabetes and effects of insulin therapy. Acta Paediatr 2001;90:860-867.

33 Rosenecker J, Hofler R, Steinkamp G, Eichler I, Smaczny C, Ballmann M, Posselt HG, Bargon J, von der Hardt H: Diabetes mellitus in patients with cystic fibrosis: the impact of diabetes mellitus on pulmonary function and clinical outcome. Eur J Med Res 2001;6: 345-350.

34 Sims EJ, Green MW, Mehta A: Decreased lung function in female but not male subjects with established cystic fibrosis-related diabetes. Diabetes Care 2005;28:1581-1587.

35 Bismuth E, Laborde K, Taupin P, Velho G, Ribault V, Jennane F, Grasset E, Sermet I, de Blic J, Lenoir G, Robert JJ: Glucose tolerance and insulin secretion, morbidity, and death in patients with cystic fibrosis. J Pediatr 2008;152:540-545, 545.e1.

36 Moran A, Dunitz J, Nathan B, Saeed A, Holme B, Thomas W: Cystic fibrosis-related diabetes: current trends in prevalence, incidence and mortality. Diabetes Care 2009;32: 1626-1631.

37 White H, Pollard K, Etherington C, Clifton I, Morton AM, Owen D, Conway SP, Peckham DG: Nutritional decline in cystic fibrosis related diabetes: the effect of intensive nutritional intervention. J Cyst Fibros 2009;8: 179-185.

38 Sullivan MM, Denning CR: Diabetic microangiopathy in patients with cystic fibrosis. Pediatrics 1989;84:642-647.

39 Lanng S, Thorsteinsson B, Lund-Andersen C, Nerup J, Schiotz PO, Koch C: Diabetes mellitus in Danish cystic fibrosis patients: prevalence and late diabetic complications. Acta Paediatr 1994;83:72-77.

40 Yung B, Landers A, Mathalone B, Gyi KM, Hodson ME: Diabetic retinopathy in adult patients with cystic fibrosis-related diabetes. Respir Med 1998;92:871-872. 
41 Andersen HU, Lanng S, Pressler T, Laugesen CS, Mathiesen ER: Cystic fibrosis-related diabetes - the presence of microvascular diabetes complications. Diabetes Care 2006;29: 2660-2663.

42 Schwarzenberg SJ, Thomas W, Olsen TW, Grover T, Walk D, Milla C, Moran A: Microvascular complications in cystic fibrosis-related diabetes. Diabetes Care 2007;30:10561061.

43 Figueroa V, Milla C, Parks EJ, Schwarzenberg SJ, Moran A: Abnormal lipid concentrations in cystic fibrosis. Am J Clin Nutr 2002, 75:1005-1011.

44 Rodman HM, Doershuk CF, Roland JM: The interaction of 2 diseases: diabetes mellitus and cystic fibrosis. Medicine (Baltimore) 1986;65:389-397.

45 Robert JJ, Grasset E, de Montalembert M, Chevenne D, Deschamps I, Boitard C, Lenoir G: Research of factors for glucose intolerance in mucoviscidosis. Arch Fr Pediatr 1992;49: $17-22$.

46 Hartling SG, Garne S, Binder C, Heilmann C, Petersen W, Petersen KE, Koch C: Proinsulin, insulin, and C-peptide in cystic fibrosis after an oral glucose tolerance test. Diabetes Res 1988;7:165-169.
47 Lanng S, Thorsteinsson B, Erichsen G, Nerup J, Koch C: Glucose tolerance in cystic fibrosis. Arch Dis Child 1991;66:612-616.

48 Swartz LM, Laffel LM: A teenage girl with cystic fibrosis-related diabetes, diabetic ketoacidosis, and cerebral edema. Pediatr Diabetes 2008;9:426-430.

49 Dodge JA, Turck D: Cystic fibrosis: nutritional consequences and management. Best Pract Res Clin Gastroenterol 2006;20:531546.

50 Lanng S: Glucose intolerance in cystic fibrosis. Dan Med Bull 1997;44:23-39.

51 O'Riordan SM HP, Hill NR, Matthews DR, George S, Greally P, Canny G, Slattery D, Murphy N, Roche E, Costigan C, Hoey HMCV: Validation of continuous glucose monitoring in children and adolescents with cystic fibrosis - a prospective cohort study. Diabetes Care 2009;32:1-3.

52 Borowitz D, Baker RD, Stallings V: Consensus report on nutrition for pediatric patients with cystic fibrosis. J Pediatr Gastroenterol Nutr 2002;35:246-259.

53 Grover P, Thomas W, Moran A: Glargine versus NPH insulin in cystic fibrosis related diabetes. J Cyst Fibros 2008;7:134-136.

54 Hardin DS, Rice J, Rice M, Rosenblatt R: Use of the insulin pump in treating cystic fibrosis related diabetes. J Cyst Fibros 2009;8:174178.
55 Reisman J, Corey M, Canny G, Levison H: Diabetes mellitus in patients with cystic fibrosis: effect on survival. Pediatrics 1990;86: 374-377.

56 Onady GM, Stolfi A: Insulin and oral agents for managing cystic fibrosis-related diabetes. Cochrane Database Syst Rev 2005; CD004730.

57 Moran A, Phillips J, Milla C: Insulin and glucose excursion following premeal insulin lispro or repaglinide in cystic fibrosis-related diabetes. Diabetes Care 2001;24:1706-1710.

58 Rosenecker J, Eichler I, Barmeier H, von der Hardt H: Diabetes mellitus and cystic fibrosis: comparison of clinical parameters in patients treated with insulin versus oral glucose-lowering agents. Pediatr Pulmonol 2001;32:351-355.

59 Kettler LJ, Sawyer SM, Winefield HR, Greville HW: Determinants of adherence in adults with cystic fibrosis. Thorax 2002;57: 459-464.

60 Abbott J, Dodd M, Bilton D, Webb AK: Treatment compliance in adults with cystic fibrosis. Thorax 1994;49:115-119. 